\title{
The Power in Our Pocket
}

\section{Tudor Calinici*}

Department of Medical Informatics and Biostatistics, "Iuliu Hatieganu” University of Medicine and Pharmacy Cluj-Napoca, Cluj-Napoca, Romania

We are living in extraordinary times. The technology is progressing in a high pace; the companies are doing their best to produce chipper, fast and powerful devices. What it was available once only to few IT specialists, now is largely available to us all at an affordable price. Few days ago, I saw a documentary in which the authors said that the computers used by NASA to send Neil Armstrong on the moon was less performant that the new iPhone released by Apple. Isn't it something?

On the way to the moon, the astronauts quickly passed the clouds, but now the technology returns to it. Cloud applications are more and more popular. It is more convenient in many ways to adopt a cloud strategy for the software applications needed by the company. The cost of the entire expensive infrastructure-servers, firewalls, 24/7 available specialists-is reduced. The quality of the "players" on the cloud market is indisputable, and the cloud applications work increasingly better and replace the existing local applications.

There is also a new tendency for health related software applications. If, few years ago, all the health related service providers tried to find software applications to fit their individual and specific problems, now, the focus is on the integration. The data systems of the hospitals are exchanging information with the social service data system, with the insurance company's data systems and with many and many stakeholders which have interest and are entitled to access that information.

The success of Web 2.0 technology produced another big shock on the way that the information is obtained and processes in health related domains. Now, not only the medical registrars are introducing the medical records into the health related data systems, sometime the patient himself is introducing his own data. The facile access to numerous sources of information-web sites, forums, communities-and the developing of many applications for home use that interprets medical parameters, create a new kind of patient-the informed patient. The informed patient is a pretentious person, always ready to check out any information. He is aware of the existence of technology and he is expecting that the health related professionals to use it.

In this context, the use of the mobile technology by the health care professionals seems to be the adequate solution. With the capacity of data-processing increasing between the generations of the same product, with the larger and high resolution screens, with the capacity of recording high fidelity photos, videos and audios, with the capacity to connect via internet from (almost) any place and (almost) anytime, the mobile smartphone seems to be the ideal tool. And, as the cherry on the ice-cream, the health-related services institutions will make a big economy in the budget for equipment. Being a very popular gadget, many health related professionals will prefer to use their own mobile smartphone, which is more performant than the one provided by their institution.

This is very tempting, but is it good? We have the technology, but are it safe to access the medical records with the same device used to access, for example, social networks? The recent "Wannacry" virus will be a funny joke comparing to a mass infestation of the databases containing medical records.

So, we have the power on our pocket. Will we be able to use it wise? I'm looking forward and confident to the future to see that.
${ }^{*}$ Corresponding author: Tudor Calinici, Department of Medical Informatics and Biostatistics, "Iuliu Hatieganu" University of Medicine and Pharmacy Cluj-Napoca, Cluj-Napoca, Romania, Tel: 0374834502; E-mail: tcalinici@umfcluj.ro

Received May 29, 2017; Accepted May 30, 2017; Published June 01, 2017

Citation: Calinici T (2017) The Power in Our Pocket. J Health Med Informat 8: 264 doi: $10.4172 / 2157-7420.1000$ e144

Copyright: (c) 2017 Calinici T. This is an open-access article distributed under the terms of the Creative Commons Attribution License, which permits unrestricted use, distribution, and reproduction in any medium, provided the original author and source are credited. 